\title{
Respect-work and College Students' Occupational Values
}

\author{
Haiyan Zhao \\ Dalian University of Technology \\ Dalian Medical University \\ Dalian, China \\ e-mail:28544492@qq.com
}

\author{
Yanjun Dai \\ Dalian University of Technology \\ Dalian, China \\ e-mail: daiyj@dlut.edu.cn
}

\begin{abstract}
Professional morality is the important part of college students' comprehensive qualities, and respect-work spirit is the footstone of professional morality. At present, the grim situation of college students has become a general topic concern of the society, and college education should pay high attention to the regression and reconstruction of college students' respect-work spirit, and it's also should lay stress on them and reflect seriously. The text tries to interpret the connotation of respect-work spirit by socialism core values. Aimed at the absence of college students' respect-work spirit, it puts forward some effective approaches to enhance the education of respectwork spirit such as paying attention to classroom teaching, structuring campus culture, developing practical activities and enhancing college students' self-discipline. It will be of great importance in uplifting college students' employment competence comprehensively.
\end{abstract}

Keywords-respect-work;college students; occupational values

\section{INTRODUCTION}

In the history of our party, the 18th National People's Congress generalizes the basic contents of socialism core values in 24 words for the first time: 'We advocate prosperity, democracy, civility, harmony, freedom, equality, justice, rule of law, patriotism, dedication, integrity, friendship, and actively foster people's socialism core values.' Dedication is the basic moral value pursuit that the citizens should set up in the socialist country. College students form the youth group that who has lots of knowledge, new ideas, vigorousness, and they are the hope to revitalize the Chinese nation. Building the respect-work spirit is one of the signs that one's important thinking of being ready to enter society has matured. From the point of needs of subject and whether the object can satisfy the needs of subject, values studies and evaluates the phenomenon of various substances and spirit, and the significance of people's behavior for individual and society. Occupational values reflect the relation between people's needs and social profession attributes. College students' occupational values reflect the relation between college students' needs and social attributes. Thus enhancing the education of college students' occupational values and fostering the lofty professional morality of respect-work, is the important link of guiding college students to understand the society, know themselves and changing their ideas about employment.

\section{THE CONNOTATION OF RESPECT-WORK SPIRIT IN THE NEW ERA}

Since ancient times, Chinese nation has always had the good traditions of 'respecting work and enjoying company', 'being devoted to the duty', 'being in charge and seeking its politics'. As the traditional virtue and excellent quingity, the basic meaning of respect-work spirit includes two aspects in traditional Chinese ethic. On the one hand, it refers to the attitude of interaction with others. Analects of Confucius · YanYuan said: 'Gentleman is dedicated without mistakes, and treat others respectfully and politely'. It means gentleman doing things in a conscientious, serious way, without mistakes, and treating others with politeness and respect. On the other hand, it refers to the spirit of taking charge of job. Analects of Confucius' Zi-Lu records: 'Being cautiousness and earnest when doing things, being allegiant and genuine'. According to Confucianism, life and work is consistent. No matter of the occupation, please make all-out efforts, please treat the work of your own hands and the professional labor in a respectful and devout attitude.

The basic requirements of the socialist professional morality include: 'loving your work and being devoted to it, being honesty and keeping your word, being fair and just in handling affairs, serving the masses, making contributions to society'. If college students want to be in the active position in the course of employment, to get ideal jobs and to win in the starting point of career development, they must improve their professional moral level — especially good respect-work spirit.

The spirit of loving and being passionate about work. You should love the work when you are at the posts, and respect and be passionate about work. Respect-work spirit first shows strong professional glory and lofty professional dignity. It requires the employee to have self-identification and aggressiveness, to integrate themselves and their cause, accordingly, they will be in high spirits and good mood. Respect-work is a virtue, and passion about work is a kind of realm. Respect-work needs to respect one's own job. Each post assumes responsibility for certain social functions, and it is the public role that the employees play in the social division of labor. At this stage, employment doesn't only mean obtaining the source of income, but also performing social functions. Relatively it may be easy to love the position that 
has good conditions and high pay, but to some positions that with harsh environment, heavy exertion or risk factors, it isn't that easy. Under the circumstances, people who love the positions and work hard with respect-work spirit, are that who have noble qualities and moral sentiments.

The spirit of hard working and dedication. Occupation isn't only the way to make a living, but also the social responsibilities that everyone should undertake. Respect-work spirit usually shows the strong sense of ownership, the concept of serving the people and the high vocational responsibility. It requires practitioners to be cautious and conscientious, to fulfill the duties, to devote to work and to take pleasure in hardship. Actually, to say the least, as long as keeping doing one's job, it is laying the solid foundation for dedication to society. The spirit of dedication is instantiated in the requests of loving work and being devoted to it, being honesty and keeping your word, serving the masses all the way. Dedication doesn't mean abnegating individual legitimate interests and happiness. It mainly refers to a kind of spirit, that is, when you choose between public and private, justice and benefit, dedication and demand, you should put the former first. Respect-work is the foundation of dedication, passion is the precondition, hard working is the origin, and dedication is sublimation of respectwork.

The spirit of precision and innovation. 'People who have respect-work spirit, always concentrate on his cause. It doesn't only require practitioner to have willingness and work hard, but also to fully exert their subjective initiative, and continuously to improve working efficiency. Respect-work is foundation of precision, and precision is sublimation of precision. Precision is a kind of strength, and strength is foundation of precision. Strength of precision is created by unremitting study and arduous experiences. Precision is a kind of action, and action is origin of precision. Only action can incarnate attitude and test strength. Innovation is the soul of a nation's development, and work can't do without innovation. Therefore, the proposal of innovative development will point the way to college students' future development. Taking innovation as the persistent pursuit, college students in the new era should have the broadmindedness and presence of 'Sometimes long Brave Wind, and also to Fan Chai sea ', and blaze new trails in a pioneering spirit. They should throw themselves into work with the spirit of perseverance, the positive mindset and indomitable will.

\section{The Actuality of College Students' OCCUPATIONAL VALUES}

The conversion from negative statedependent to the aggressive one. In the survey, more than $90 \%$ of the students approve the employment form of "two way choice and independent option", and in the survey about "the key factor of finding employment", $86.1 \%$ of the students believe that personal comprehensive strength is the key factor. In the survey about "the mode of job selection", 78.3\% of the students choose on-site recruiting in various talents exchange fair, $10.3 \%$ of the students choose media advertisement involved online job search, and only $5 \%$ of the students choose to find job through social networks.
The view of choosing job by being employed first, choosing suitable job has evolved. In market economy conditions, people have independent choice of living environment that they like. Everyone can have multiple and two-way selection on the basis of market requirement, comprehensive value such as professional nature, labor intensity and individual hobbies, development requirements and so on. The one-step employment process has changed to the phased implementation, and it has become the contemporary college students' realistic way of job selection. In the survey, $52.4 \%$ of the students express that they will choose job by being employed first, choose suitable job and then start, and they widely accepted the viewpoint of "shortterm and transitional job selection", "search unemployment", "strengthening themselves after finding jobs".

Emphasis about self-worth, paying attention to selfdevelopment, highlighting individual-based values. In the survey, the first four that reside in "professional value orientation" are "making their own self-worth be acknowledged", "enjoying a higher level of material life", "playing their interests and passions", "consummating personal ambition"; and in the survey about "What is the dominant motive that you strive for", the first four are "adapting to the society, finding a good job and living a better life", "proving their worth", "standing out among people", "reciprocating parents and family". Thus it can be seen that college students will give priority to pursue self-development and self-worth fulfillment when they find jobs, and individual-based values has been widely acknowledged in today's college students group.

Job objective shows diversification tendency. Paying attention to the hierarchy is the major trait of traditional occupational values. When people choose careers, they usually consider the state-run one first, then collectivity, big collectives first, then small collectives, and when they choose posts, usually office first, then production line. Contemporary college students' choice about employment units is more diversified, and overseas-funded enterprises, private enterprises, three kinds of investment enterprises are all the main objectives when they choose jobs. In recent years, an increasing number of college students lean to start their own business, from obtaining employment to do pioneering work, it isn't only the fundamental transformation of contemporary college students' mentality about employment, but also the fundamental transformation of traditional occupational values.

\section{The PRESEntation And CAUSE of College STUDENTS' RESPECT-WORK SPIRIT ABSENCE}

Inaccuracy of college students' value orientation of their own. Because of the shallow social experience and less living practice, contemporary college students usually have higher expectation about future, and the orientation about their own value aren't accurate. Today's colleging has turned to popular education from traditional elite education, and people's view about college students' value tends to be objective and rational, and people pay more attention to students' ability in practical work and the value that they have created. However, because of the cognitive difference between the cognitive subject such as enterprises, society and college students, it goes awry 
between college students' personal expectations and their actual social value, thus there is the phenomenon that respectwork spirit absence such as more dissatisfaction about jobs and less down-to-earth spirits. Simultaneously, with the constant improvement of material and cultural life, people's pursuit is more diversified, and undesirable phenomenon permeates the society. College students are in such an important period that their value forms, so they are easily to be eroded. Because of the influence by diversified values, college students' ideology reflects in identification about leaning, some students think study is useless and money is fundament, so they are indifferent to learn culture and knowledge. In addition, some college students question the traditional admirable respectwork spirit such as the spirit to bear hardships and hard work and be passionate in the jobs, and then comes the unethical phenomenon such as blundering psychology, making no attempt to make progress, muddling through the work and so on.

The reasons for respect-work spirit education absence has the following several aspects. Firstly, because of the influence by traditional view, people's cognition about college students' value and social position is short of objectivity and scientificity, and family, school, society lack education to students about the spirit "to bear hardships and hard work, being concentrative and hardworking, being down-to-earth", thus it leads to some college students lack proper and rational judgment about outlook on life and value such as "lost" and "acquision", "success" and "loss", "sweet" and "bitter". Secondly, in order to raise employment, some colleges lack scientificity and systematicness in daily education, system and management, professional ethics education legging behind, and they lack superior consciousness about education. Thirdly, some colleges' educational ideas are behindhand, and they don't establish the concept of "all-rounder, generalist", and they still follow the traditional exam-oriented educational mode, regarding scores as the only criterion to measure students' performance, ignoring to cultivate and enhance college students' comprehensive abilities and quality.

\section{COUNTERMEASURE OF CULTIVATING AND}

\section{Propagating COLlege StUdents' RESPECT-Work SPIRIT}

Firstly, enhancing education of socialism core values to college students. Under the new situation of college students' weaker social responsibility consciousness, self-awareness prominence, professional ethics absence, it is imperative to enhance education on socialism core values. College should integrate the content system of socialism core values education according to current college students' features, except infiltrating socialism core values education in "Two-course" teaching, they should base on other subjects' characteristics and advantages and bond teaching practice closely to bond socialism core value system and other subjects' content organically. Meanwhile, they should define the education point of socialism core values to the new generation of college students. On the one hand, they should make great efforts to enhance professional ethics education, and guide college students to foster the professional spirit of being passionate in their work. On the other hand, college students have to face the complicated situation of national needs, social responsibilities and personal interests in employment, in order to lead college students to set up correct professional value orientation, they should enhance the education of socialist concept of justice and benefit to college students.

Secondly, giving fully play to the edifying influence of campus culture and building a good educational environment. Colleges should take advantage of all the campus culture, and infiltrate the respect-work spirit to various parts of college students' study and life. When college students accumulate specialized knowledge, colleges should give them futureoriented education, and build a educational environment of occupational values that has exalted spirit. At present, campus community activity which is approved by students and has active participation, can be the important channel to cultivate college students' respect-work spirit. In addition, system of student cadres is also the good channel to cultivate college students' respect-work spirit, no matter which work, they should guide students to take it seriously and be conscientious, hard-working. At the same time, it can be the role model, influence and drive college students' respect-work spirit with self-cultivation and establishment around and universally. College also can make use of various objective entities, such as constructions, campus scenery, natural goods and sundry facilities, to transmit and build good educational environment that plays the positive role and with silent unburdening. It can set personalized slogans and inspirational brands, bulletin board, and it doesn't only cultivate college students' taste, but also are conducive to guide college students to set up correct views of professional values.

Thirdly, strengthening vocational guidance, fostering college students' respect-work spirit in social practice. Firstly, correcting college students' occupational values. Setting up the well occupational values and professional ethics is the right way to realize the value of life. Just as Marx said in the Reflection of a Young Man on the Choice of a Profession :"Man's nature is so constituted that he can attain his own perfection only by working for the perfection, for the good, of his fellow man". Next, colleges should attach great importance to the education during the period of vocational adjustment. Colleges can set career guidance curriculum, hold employment knowledge lectures, invite the staff of labor and personal department to give lectures to students or outstanding graduates to communicate and other various forms, which can help college students deepen the understanding of the society, master the responsibilities, rights and obligations the professional role should manage, intensify professional ideal and emotion and improve the match degree of "harmony between people and profession". Holding social activities. Colleges can take measures of "opening the gate and connecting with the society", combine with interior and exterior, and let the social resources give full play, by visiting, practicing, social survey, visiting model workers and so on, it can cultivate college students" "six kinds of spirits", that is sense of crisis, sense of competition, sense of innovation, awareness of paying back society, awareness of hard work, awareness of re-employment, and it can temper their respectwork spirit.

Fourthly, college students should strengthen ideological and moral cultivation consciously, and build the groups image 
of dedication. College students aren't only the intellectual elites, but also the moral model, and they should give an example of loving their work and being devoted to it for the whole society. Firstly, fostering a correct occupation concept, forming well occupational habit. Labor is the source of life value, and the extent that fruits of labor meet society's needs is the measure of human value. College students should work in a well-grounded way and be cautious and conscientious, and create their own life values. Next, establishing a correct consumption concept, carrying on the fine tradition of hard work. Hard work that we advocate today, it doesn't mean being industrious and frugal in life, and the more important is being immersed and devoting in production and work. Finally, developing correct study and living habits, realizing coordinated development of knowledge, ability, diathesis. College students should handle properly the relation between profundity and pureness, extension and profundity, theory and practice, and study assiduously the technical expertise of operating post, and achieve "three kinds of correctness", "three kinds of happiness". That is treating themselves in a right way, treating others in a right way, treating society in a right way; taking pleasure in helping people, being contented with everything, enjoying yourselves frequently. Please stay physically and mentally healthy, and make yourselves be the compound talents with specialty, capability and knowledge.

\section{REFERENCES}

[1] Arthur M.B \& Hall D.T. "Handbook of career theory". Cambridge: Cambridge University Press, 1989.

[2] Zhou Changchun."To Explore the College Students' Ideological and Political Education Under the New Situation". Beijing: Beijing University of Technology Press, 2005.

[3] National Medium and Long-term Plan for Education Reform and Development. (2010 2020).

[4] Song Jianxiang. "The Analysis and Countermeasures of The Factors Influencing on Career choice" .Chinese College Students Employment. Beijing, pp.35, August 2014 .

[5] Qin Huayan. "The Analysis of College Students' Professional Spirit Cultivation and Practice". Journal of Jilin Institute of Education. Changchun, October 2014.

[6] Xiong Wanlin, Li Chao. " A Study of College Students'Vocational Values". Wuhan, November 2014. 